\title{
Investors in People: what is it all about?
}

\author{
P. Cannell,
}

\section{Recently, there has been a proliferation of press releases from organizations recognized as Investors in People including the BDTA, the DPB, the BDA and many individual dental practices. ${ }^{1,2}$ Indeed, the number of dental practices recognized as Investors in People has more than doubled in the last six months. What is this sudden interest in Investors in People within the dental profession all about? This article is a guide to what the Investors in People (liP) standard is, what relevance it has to dental practice and what benefits can be gained from working towards this standard. I have used my own experiences in gaining the standard in our dental practice to act as an example throughout the article.}

\section{What is Investors in People?}

IiP is a business quality standard that was developed in 1990 by the National Training Task Force in partnership with, amongst others, the CBI, the TUC and the Institute of Personnel and Development (IPD), and was supported by the Department of Employment. Research was carried out into what made successful businesses effective and retain their effectiveness through periods of change and increased competition. This lead to the development of the standard; a set of indicators of good business practices that any organization, large or small, can measure itself against. ${ }^{3}$

The 12 indicators that make up the standard are based on four key principles.

- Commitment to develop all the people within your organization, including yourself, to meet your practice's objectives.

- Planning the training and development of all your staff to help achieve these objectives.

- Action to carry out the appropriate training and development in a continuing programme that is related directly to the business objectives.

- Evaluation of the outcomes of training

$1^{*}$ Dental Surgeon and Associate Management Consultant, UMD Professional, Chalkwell Dental Practice, 10 Leigh Road, Leigh on Sea, Essex, SS9 $1 L D$.

${ }^{*}$ Correspondence to: Phillip Cannell

ReFEREED PAPER

Received 09.04.01; Accepted 01.05.01

(C) British Dental Journal 2001; 191: 175-178 and development for individuals and the practice as a whole, as a check to ensure that the investment has been worthwhile and that it has helped lead to achievement of the business objectives.

Each principle is vital to the success of the others. The 12 individual indicators are divided between the four key principles.

\section{Commitment}

1. The organization is committed to supporting the development of its people. In reality this means that your organization must communicate to its staff that it wants to improve its performance by appropriate training and development of its people. A practice staff meeting could be an ideal opportunity to do this.

2. People are encouraged to improve their own and other people's performance. A way of achieving this might be to use an appraisal system to review how effective different members of your team are at their particular role, and to work out ways together to improve in areas that require it.

3. People believe their contribution to the organization is recognized. This could be financial recognition (ie rewarding individuals that achieve a further qualification), praise or positive feedback at an appraisal or staff meeting or by the use of press releases to recognize training successes.

4. The organization is committed to ensuring equality of opportunity in the development of its people. Everyone in your organization should be given equal opportunities to develop.

\section{Planning}

1. The organization has a plan with clear aims and objectives that are understood by everyone. This involves deciding exactly what sort of practice you want to run. The answers to this question may be many and varied. For example, you may wish to run a super efficient healthservice based practice, with targets for total patient numbers, new patient enquiries, turnover and profitability. Alternatively, you may be starting a specialist periodontal referral practice with targets for referrals from local practitioners. Communicating your objectives with your staff, perhaps by means of a staff meeting, ensures that everyone knows what the practice is trying to achieve and the direction in which it is going. This encourages staff to contribute their ideas towards these goals. It is my experience that those who do not share the vision that the practice principal has for their practice often tend to self select and leave that organization. The article, Marketing for the Slightly Uncertain -What Business

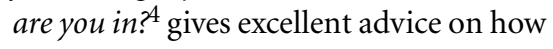
you might define what your objectives are for your practice.

2. The development of people is in line with the organization's aims and objectives. In essence this means that the training that any of your staff, including yourself, undertakes should be closely linked to helping to deliver the objectives of your practice. In the examples above it might be appropriate for certain practice members to undertake training in promotional and marketing skills to help the practice achieve its targets for new patient enquiries.

3. People understand how they contribute to achieving the organization's aims and objectives. Each of your staff need to know what their role is and how it contributes to the overall aims of the practice. For example, a practice manager whose job description includes practice promotion needs to be aware that this role is fun- 
damental to helping the practice achieve its objectives relating to attracting new patients.

\section{Action}

1. Managers are effective in supporting the development of people. It is all very well planning what you are going to do with your practice, but you now have to put that plan into action. This means that where an objective has been identified, the people and their current skills and knowledge in the relevant area need to be assessed against what is going to be required of them. This can be achieved by means of a training needs analysis, which simply means a method of identifying an individual or group who requires training to be better able to do their job. If people need further training, this can be found. It may take one of several forms; attending a relevant course, reading an article or book or assigning a competent coach or mentor to the trainee can all be effective. It should be borne in mind that what is the most effective method of learning for one individual is not necessarily the same for the next.

2. People learn and develop effectively. This can be achieved initially by inducting new members of staff; making sure that they are introduced as quickly as possible to their new organization in order that they can start to contribute from day one. A good time to address people's learning and development is at their appraisal. Reaction to any previous training can be gauged and areas for future development for the benefit of the member of staff and how that fits with the objectives of the dental practice as a whole can be discussed.

\section{Evaluation}

1. The development of the people improves the performance of the organization, teams and individuals. It is essential to evaluate whether training has been successful at improving the performance of individuals and teams within the practice and the practice as a whole. In other words, are the objectives set at the planning stage now being realized? If not, perhaps the wrong kind of training has been

\section{Each of your staff need to know what their role is and how it contributes to the overall aims of the practice.}

selected, delivered in the wrong way or the objective may have been unrealistic.

2. People understand the impact of the development of people on the performance of the organization, teams and individuals. It is important that all your staff understand the link that their individual development has on the practice as a whole. Knowing that what you do has a key part to play in the success of the whole business can be very motivational.

3. The organization gets better at developing its people. Another important reason to evaluate training is that if problems have occurred with the training activity, improvement can be made in subsequent training activities so that time and money spent on training is used to best effect.

The standard is achieved through a planned approach. Initially, an organization needs to measure itself against the set of indicators. This is achieved by means of a diagnostic assessment, where an advisor visits an organization to establish which of the indicators are already being met and which require further work. This may be done by direct discussion with the staff within an organization, by the use of questionnaires or perhaps a combination of the two.

This process might sound confrontational but should not be viewed as such. The real essence of the diagnostic visit and the manner in which it is carried out is to objectively establish areas that need development to help the business in question become more effective.

Our diagnostic assessment showed that we met very few of the indicators fully, some partially and some not at all. In order to help us achieve all the indicators fully an action plan was created. This is a set of points that need to be addressed to meet the indicators fully. For instance, if we consider the indicator, 'People learn and develop effectively', it was felt that it would be beneficial to our practice to introduce an induction programme for new members of staff to introduce them quickly and thoroughly to our practice to get them learning and up to speed from day one. We also needed to introduce an appraisal system to review how successful staff training and development initiatives had been.

Fundamental to achieving an effective business is having a business plan. This can be a complex document looking at every aspect of how your practice runs, but essentially the most important part of a business plan is the setting of business objectives; clear, specific goals that are measurable, achievable, realistic and time-bound (SMART).

An example of a SMART objective for a dental practice might be to increase profitability (specific) by a certain percentage (measurable, achievable and realistic) within a fixed time frame (time bound). Grace and Stuart-Wilson ${ }^{4}$ look in detail at the issue of setting SMART business objectives for a dental practice.

These objectives need to be communicated to the people within your organization, perhaps by a staff meeting or by discussion with individual staff, so that the direction of the practice is clear to everyone. Training and development of people within the organization where it is required to help meet the business objectives should follow. For instance, telephone skills training may be appropriate for a reception team to help achieve an objective of improving customer care.

\section{Why commit towards the standard?}

One of the difficulties of working in a normal dental practice is the pressure of events that usually leads to reactive rather than proactive behaviour. For example, most of the dentist's time is taken up with treating patients, yet all the administrative matters and management issues also need to be fitted into a day that has a full appointment book. Many dentists only schedule patients into their day and then try to fit in all the 


\section{OPINION dental business}

demands of running a business as best they can. This usually leads to a stressful environment, helping create a feeling of loss of control and the resultant sequelae in terms of inadequate planning and people management. The whole thing then deteriorates into a vicious cycle.

\section{Management principles}

Why does this sequence of events seem to be the norm rather than the exception within dental practice? For undergraduates at dental school the teaching focuses on providing the skills and knowledge required to allow them to undertake clinical dentistry. However, running a dental practice involves so much more than simply being competent to practise. The problem is compounded by the fact that as dentists we often do not know what we need to know in relation to running a practice. This is because management theory is not an area that we have been exposed to at under- or postgraduate levels or appreciate the potential value of. A glance at the courses section of the BDJ and other publications provides a multitude of opportunities on every clinical speciality, but courses on effective business management and its relevance to dental practice are rare. Consequently, all too often dentists look for 'tips' on how to run their practices when what they actually need is knowledge of sound, tried and tested management principles that work in successful organizations and that can be applied to dental practice.

To illustrate this, I wonder how many dentists have considered what effect their leadership ability has on their practice. Very few people are born good leaders, most have to work at it and there are many texts written on and courses devoted to it that are as relevant to dental practice as they are to any small business. The same can be said of people management. I have often heard practice owners recounting stories of how a member of staff who they had considered to be a loyal member of their team had resigned from their practice, but they have no idea what prompted this action or, perhaps more importantly, how it could be avoided in the future.

This is where IiP fits in, as it offers a framework for improving the performance

\section{IiP...offers a framework for improving the performance of an organization through people performance, including the practice}

\section{owner.}

of an organization through people performance, including the practice owner.

There were several reasons why our practice decided to commit towards the standard. We felt very much that we needed to take more control of where the practice was going and we realized that we required new skills and knowledge to achieve this. The emergence and development of corporate bodies within the dental profession made us feel that in order to compete in this changing environment we needed to be managing our practice as well as we possibly could. Because we were aware of the increase in consumerism we felt that for our practice to be successful we needed to look carefully at the non-clinical, customer service issues which often form the basis of patients' judgements about a practice rather than the quality of the clinical dentistry they receive.

\section{Hands on management}

Our method of achieving IiP was a little different from the traditional method that many organizations have used in the past. Most businesses engage a consultant to help them achieve the standard, but we were fortunate enough to be introduced to a concept that has been developed as a follow-up to the BDJ Management Research Initiative (MRI), which was introduced in 1994. Instead of working towards the standard on your own, the 'Hands On Management' programme provides a group of practices with a six-month programme of two-day workshops (one weekend a month) covering general business management. Thus the workshops are intended to provide the necessary skills and knowledge to enable the dentists to understand how to run an effective business and as a result the practices will qualify for the IiP standard. It is important to appreciate that the 'Hands On' programme does much more than simply help to obtain IiP and thus the value is much greater. A further benefit is that the overall cost is much less for individual practices than it would be using the traditional consultancy route.

The 'Hands On Management' workshops have been running successfully in many parts of the country since January 1999. ${ }^{5}$

\section{What are the benefits of liP ?}

Much research has been carried out on organizations that have undertaken $\mathrm{IiP}^{6}$ and the findings suggest that the same benefits are often present. These include an increase in profitability, improved motivation and morale of staff through greater involvement, personal development and recognition of achievement and improved customer satisfaction as employees tend to become more customer focused.

Within my own practice we achieved our objective of increasing profitability by $20 \%$ within six months of committing towards IiP. Effective staff meetings, use of performance review and analysis of the training needs of all staff to help achieve our objectives ensure that we are all clear on the direction of the practice and the importance of our roles within it. Putting good management principles in place has involved the staff much more than they previously had been. In addition, training successes of individual staff, recognized by use of press releases, all help increase staff motivation. Absenteeism has reduced, as has staff turnover and groups within the staff meet to debate how they can better their department's performance. Staff believe that the practice is part of who they are rather than just a place where they go to work.

Besides these practical benefits, achieving Investor in People status brings with it public recognition, which at our practice has manifested itself through increased local media attention and a marked increase in new patient enquiries. When we 
have needed to recruit new staff our Investor in People status has helped set us apart as an employer and we have noted a larger number of higher calibre candidates applying. We also entered and won the Best Dental Team Support Programme at the Dental Awards 2000, which again has brought with it much local interest in the practice. I mention this only to again illustrate what can be achieved through working towards IiP. Prior to committing, we would not have even contemplated entering such an award.

I personally feel that I have gained one overwhelming benefit from working towards IiP that I did not have before and that is the feeling of being in control of my practice.

\section{Taking the first step}

One of the questions often raised by dentists considering the idea of undertaking IiP is that it might take up too much time or generate many more administrative tasks, thereby reducing the time available for treating patients and generating income. This, however, misses the point somewhat, which is not just to achieve Investors in People recognition, satisfying as it is, as an end in itself. The point of working towards IiP is to put good business practice principles in place within your organization to make it much more effective, achieving and delivering the things that you want it to.

Nevertheless committing towards IiP does involve making a leap of faith and should not be undertaken half-heartedly. In particular, in practices where there are several partners, it is vitally important that all are in agreement as to why they are embarking on the process from the outset and that they are all equally committed. However, the number of practices that are either working towards or who have achieved IiP have been rapidly increasing over the last 18 months and their experiences should be a source of encouragement to those considering working towards IiP.

If you wish to find out more about IiP you should contact your local Learning and Skills Council (LSC) or Small Business Service (which replaced Training and Enterprise Council and Business Link in April 2001) in England and Wales, the Scottish
Enterprise and Local Enterprise Councils in Scotland and the Northern Ireland Economic Development Partnerships in Northern Ireland. These are bodies licensed to deliver the standard. Alternatively, you can approach an accredited IiP consultant who can liaise with the appropriate body. It is helpful if your consultant has experience of working with dental practices.

\section{Conclusion}

Dentistry as a profession tends to be very sceptical of anything that appears 'non-dental. However, Investors in People is extremely relevant to the business of dentistry and there are many practices that are now benefiting from improved management techniques that have arisen through working towards IiP.

$1 \quad$ News and notes. Br Dent J 2000; 189: 109.

2 Dobson R, Dobson S. Investing in People. Ind Dent Sept 2000; 5: 41-43.

3 The Investors in People Standard. Investors in People UK 2000.

4 Stuart-Wilson F, Grace M. Dental Business 1998; 2, 2-7.

5 News and notes. Br Dent J2000; 189:393.

6 Research Directory. Investors in People UK. 